\title{
Dipeptidyl peptidase 4 (DPP-4) inhibitors and cardiovascular outcomes in patients with type 2 diabetes mellitus (T2DM): a systematic review and meta-analysis
}

Dan Liu' ${ }^{1 *+}$, Biao $\mathrm{Jin}^{2+}$, Wei Chen ${ }^{2}$ and Peng Yun ${ }^{1}$

\begin{abstract}
Background: Dipeptidyl peptidase 4 (DPP-4) inhibitors are newer oral anti-diabetic agents which have been approved by the Food and Drug Administration for the treatment of patients with type 2 diabetes mellitus (T2DM). In this analysis, we aimed to systematically compare the cardiovascular outcomes associated with DPP-4 inhibitors versus non-DPP-4 inhibitor users.
\end{abstract}

Methods: All English publications that compared the use of DPP-4 inhibitors and that reported cardiovascular outcomes in patients with T2DM were searched using specific terms. Studies were included if they satisfied the following inclusion criteria: They were randomized trials or observation cohorts/registries comparing DPP-4 inhibitors use in patients with T2DM; The studies included a large sample size of participants; And they reported cardiovascular outcomes as their main endpoints. RevMan 5.3 was used to analyze the data, and odds ratios (OR) with 95\% confidence intervals (Cl) were used to represent the results.

Results: A total number of 157,478 participants with T2DM were included. Seventy-six thousand and twenty six patients were assigned to the DPP-4 inhibitor group whereas 81,452 patients were assigned to the control group. Results of the current analysis showed that during a mean follow-up time period ranging from 52 to 152 weeks, the primary endpoint (cardiovascular death/non-fatal myocardial infarction (MI)/non-fatal stroke) was not significantly different in the treatment of T2DM patients with versus without DPP-4 inhibitors (OR: 0.95, 95\% Cl: 0.86-1.04; $P=0.26$ ). Cardiovascular death (OR: 1.00, 95\% Cl: 0.90-1.10; $P=0.93)$, stroke (OR: 1.03, 95\% Cl: 0.89-1.18; $P=0.72)$, MI (OR: 0.97, 95\% Cl: 0.88-1.07; $P=0.59)$, all-cause mortality (OR: 0.84, 95\% Cl: 0.59-1.18; $P=0.31)$, hospitalization for cardiovascular complications (OR: 1.02, 95\% Cl: 0.96-1.09; $P=0.45$ ) and hospitalization specifically for heart failure (OR: 1.05, 95\% Cl: 0.90-1.23; $P=0.55)$ were also similarly manifested in both groups.

Conclusion: The current analysis showed that treatment with DPP-4 inhibitors did not significantly increase cardiovascular outcomes in these patients with T2DM indicating that those drugs might be safe to use in terms of cardiovascular events.

Keywords: Dipeptidyl peptidase 4 inhibitors, Type 2 diabetes mellitus, Cardiovascular outcomes, Cardiovascular death

\footnotetext{
* Correspondence: liudan315@163.com

†Dan Liu and Biao Jin contributed equally to this work.

${ }^{1}$ Department of Endocrinology, Jingzhou First Peoples Hospital, Jingzhou,

Hubei, People's Republic of China

Full list of author information is available at the end of the article
}

(c) The Author(s). 2019 Open Access This article is distributed under the terms of the Creative Commons Attribution 4.0 International License (http://creativecommons.org/licenses/by/4.0/), which permits unrestricted use, distribution, and reproduction in any medium, provided you give appropriate credit to the original author(s) and the source, provide a link to the Creative Commons license, and indicate if changes were made. The Creative Commons Public Domain Dedication waiver (http://creativecommons.org/publicdomain/zero/1.0/) applies to the data made available in this article, unless otherwise stated. 


\section{Background}

At present, even if all the patients with type 2 diabetes mellitus (T2DM) do not have the same risk, enough evidence is available regarding the occurrence of cardiovascular disease (CVD) in patients with long-standing uncontrolled T2DM [1]. Scientists are trying to develop oral hypoglycemic agents which while maintaining the blood sugar level to a constant level, could also reduce the rate of cardiovascular events.

Recently, due to the fact that oral hypoglycemic drugs while significantly maintaining a normal blood glucose level, could paradoxically increase cardiovascular events in patients with T2DM [2], the Food and Drug Administration (FDA) ordered to demonstrate their safety prior to seeking approval. Because of this reason, several newer anti-diabetic agents have undergone randomized placebo-controlled cardiovascular outcome trials (CVOT) which mainly involved patients with preexisting CVD and patients who were at a higher risk of developing this serious chronic disease [3].

Dipeptidyl peptidase 4 (DPP-4) inhibitors are newer anti-diabetic agents which have shown to well maintain blood glucose level over the long-term (decent glycated hemoglobin [HbA1c]), and were not associated with hypoglycemia or weight gain in comparison to other similar drugs [4]. However, there was a need for a systematical evidence to show the impact of DPP-4 inhibitors on cardiovascular outcomes in such patients.

In this analysis, we aimed to systematically compare the cardiovascular outcomes associated with DPP-4 inhibitors versus non-DPP-4 inhibitor users for the treatment of a large number of participants with T2DM.

\section{Methods}

Databases used during the search process

The search process was carried out with reference to the PRISMA guideline [5]. Medical Literature Analysis and Retrieval System Online (MEDLINE) and its interface PubMed, biomedical and pharmacological bibliographic database Excerpta Medica database (EMBASE), Cochrane database and www.ClinicalTrials.gov were searched for relevant publications.

\section{Search strategies and search terms}

All English publications that compared the use of DPP-4 inhibitors and reported cardiovascular outcomes in patients with T2DM were searched specifically using the terms: "dipeptidyl peptidase 4 inhibitors and type 2 diabetes mellitus", "dipeptidyl peptidase 4 inhibitors and diabetes mellitus and cardiovascular outcomes", "dipeptidyl peptidase 4 inhibitors and cardiovascular outcomes", "dipeptidyl peptidase 4 inhibitors and cardiac", "DPP-4 inhibitors and diabetes mellitus".
In addition, individual name of the drugs were also used: "sitagliptin and type 2 diabetes mellitus", "sitagliptin and cardiovascular outcomes", "sitagliptin and diabetes mellitus and cardiovascular outcomes", "saxagliptin and type 2 diabetes mellitus", "saxagliptin and cardiovascular outcomes", "saxagliptin and diabetes mellitus and cardiovascular outcomes", "omarigliptin and type 2 diabetes mellitus", "omarigliptin and cardiovascular outcomes", "omarigliptin and diabetes mellitus and cardiovascular outcomes", "alogliptin and type 2 diabetes mellitus", "alogliptin and cardiovascular outcomes", "alogliptin and diabetes mellitus and cardiovascular outcomes", "linagliptin and cardiovascular outcomes", "linagliptin and diabetes mellitus and cardiovascular outcomes", "vildagliptin and cardiovascular outcomes", "vildagliptin and diabetes mellitus and cardiovascular outcomes".

\section{Inclusion and exclusion criteria}

Studies were included if they satisfied the following inclusion criteria:

- They were randomized trials or observation cohorts/registries comparing DPP-4 inhibitors use in patients with T2DM;

- They included a large sample size of participants (note that studies with very small sample size were excluded);

- They reported cardiovascular outcomes as their main endpoints;

Studies were excluded if they consisted of the following features:

- They were literature reviews/meta-analyzes/case studies/letters to editors;

- They did not include DPP-4 inhibitor users for the treatment of patients with T2DM;

- They included a small sample size;

- They did not report cardiovascular outcomes as their endpoints;

- They were written in other languages than in English;

- They were duplicated studies.

Type of DPP-4 inhibitors, cardiovascular outcomes reported and follow-up time periods

Omarigliptin, sitagliptin, saxagliptin and alogliptin were the DPP-4 inhibitors which were used to treat these patients with T2DM as shown in Table 1.

The following outcomes were assessed:

- Primary endpoint: consisting of cardiovascular death, non-fatal myocardial infarction and non-fatal stroke; 
Table 1 Type of DPP-4 inhibitors, cardiovascular outcomes reported and follow-up time periods

\begin{tabular}{|c|c|c|c|}
\hline Studies & $\begin{array}{l}\text { Type of DPP-4 } \\
\text { inhibitors }\end{array}$ & Cardiovascular outcomes reported & $\begin{array}{l}\text { Mean follow-up } \\
\text { time period }\end{array}$ \\
\hline Gantz2017 [7] & Omarigliptin & $\begin{array}{l}\text { Cardiovascular death/non-fatal Ml or non-fatal stroke, cardiovascular related death, fatal and non- } \\
\text { fatal Ml, fata and non-fatal stroke, all-cause mortality, hospitalization for heart failure, } \\
\text { hospitalization for heart failure or cardiovascular death }\end{array}$ & 96 weeks \\
\hline $\begin{array}{l}\text { Green2015 } \\
{[8]}\end{array}$ & Sitagliptin & $\begin{array}{l}\text { Cardiovascular death/non-fatal Ml or non-fatal stroke, cardiovascular death, non-fatal MI, non-fatal } \\
\text { stroke, hospitalization for unstable angina, hospitalization for heart failure, all-cause mortality }\end{array}$ & 152 weeks \\
\hline $\begin{array}{l}\text { Park2015 } \\
{[9]}\end{array}$ & $\begin{array}{l}\text { Unspecified } \\
\text { DPP-4 inhibitors }\end{array}$ & All-cause mortality & 124 weeks \\
\hline $\begin{array}{l}\text { Scirica2013 } \\
{[10]}\end{array}$ & Saxagliptin & $\begin{array}{l}\text { Cardiovascular death/non-fatal Ml or non-fatal stroke, all-cause mortality, cardiovascular death, Ml, } \\
\text { stroke, hospitalization for unstable angina, hospitalization for heart failure, hospitalization for } \\
\text { coronary revascularization }\end{array}$ & 109 weeks \\
\hline $\begin{array}{l}\text { Shih2016 } \\
{[11]}\end{array}$ & $\begin{array}{l}\text { Unspecified } \\
\text { DPP-4 inhibitors }\end{array}$ & All-cause mortality, MACEs, MI, stroke, heart failure & 114 weeks \\
\hline $\begin{array}{l}\text { Wang2015 } \\
{[12]}\end{array}$ & Sitagliptin & Cardiovascular death/non-fatal Ml or non-fatal stroke, Ml, stroke, cardiovascular mortality & 52 weeks \\
\hline $\begin{array}{l}\text { White2013 } \\
{[13]}\end{array}$ & Alogliptin & $\begin{array}{l}\text { Cardiovascular death/non-fatal Ml or non-fatal stroke, cardiovascular mortality, non-fatal Ml, } \\
\text { non-fatal stroke, all-cause mortality }\end{array}$ & 78 weeks \\
\hline
\end{tabular}

Abbreviations: DDP-4 Dipeptidyl peptidase 4, MI Myocardial infarction, MACEs Major adverse cardiac events

Primary endpoint: including cardiovascular death/non-fatal MI or non-fatal stroke, cardiovascular related death, fatal and non-fatal MI

- Cardiovascular death;

- Myocardial infarction (MI);

- Stroke;

- All-cause mortality;

- Hospitalization for cardiovascular complications;

- Hospitalization specifically for heart failure.

A mean follow-up time period ranging from 52 weeks to 152 weeks were considered relevant as shown in Table 1.

\section{Data extraction and quality assessment}

Four independent reviewers were responsible for the data extraction and quality assessment of the trials. In the beginning, each reviewer extracted the following data: the names of the authors, the year of publication, the type of DPP-4 inhibitors, the cardiovascular outcomes, the average follow-up time periods, the total number of participants from each group, the baseline features, the duration of diabetes mellitus, the total number of cardiovascular events; and at a later stage, data were compared and cross-checked to make sure all correct data were entered.

Quality assessment of the trials was carried out with reference to the criteria suggested by the Cochrane Collaboration [6]. A maximum total score of 12 points was allotted based on the bias risk reported.

\section{Statistical analysis}

RevMan 5.3 software was used to carry out the statistical analysis of the pooled data. Odd ratios (OR) and 95\% confidence intervals (CI) were generated to represent the main analytical data throughout the result section.
Expected heterogeneity was assessed using the (1) Q statistic test whereby a result with a $P$ value less or equal to 0.05 was considered statistically significant, and (2) the $\mathrm{I}^{2}$ statistic test whereby a lower $\mathrm{I}^{2}$ value denoted a lower heterogeneity.

A fixed statistical effect model $\left(\mathrm{I}^{2}<50 \%\right)$ or a random statistical effect model $\left(\mathrm{I}^{2}>50 \%\right)$ was applied depending upon the value of heterogeneity which was generated.

Sensitivity analysis was also carried out to compare with the main results for any significant difference by a method of exclusion.

Since this analysis included only a very small volume of studies, publication bias was visually assessed through funnel plots which were generated through the RevMan software.

\section{Compliance with ethical guidelines}

This is a systematic review and meta-analysis of previously published original studies and therefore ethical approval or any board review approval was not required.

\section{Results}

\section{Search outcomes}

Electronic search resulted in a total number of 4512 publications. An initial assessment was carried out to eliminate unwanted studies, and based on relevance, only 245 full-texts were finally assessed for eligibility.

After another round of assessment, further eliminations were carried out based on the following criteria:

- Literature review/meta-analyses/case studies/letters to editors $(n=32)$;

- Cardiovascular outcomes were not reported $(n=22)$; 
- Consisted of a small number of participants $(n=49)$;

- Did not report the correct control group $(n=22)$;

- Duplicates $(n=113)$.

Finally, only 7 studies (4 randomized controlled trials and 3 observational cohorts) [7-13] were selected for this analysis as shown in Fig. 1.

\section{Main features of the studies}

Four studies were randomized controlled trials and 3 studies were observational cohorts.

A total number of 157, 478 participants with T2DM were included in this analysis. Seventy-six thousand and twenty six $(76,026)$ patients were assigned to the DPP-4 inhibitor group whereas 81,452 patients were assigned to the control group as shown in Table 2. Patients were enrolled between the years 2007 to 2017 as shown in the Table.

Based on the methodological assessment, a score ranging from 8 to 12 were allotted to the trials indicating a low to moderate risk of bias.

\section{Baseline features of the participants}

The baseline features of the participants have been listed in Table 3.
As shown in the Table, a mean age of 61.0-74.5 years were reported among the participants. Most of the participants were male patients with a mean percentage of $46.2-70.7 \%$. The duration of diabetes mellitus varied from 7.10 to 12.1 years. The participants had an average HbA1c varying from 7.20 to 8.00 years. Other features which were reported in Table 3 included the percentage of participants with hypertension and current smoker.

\section{Analysis of the cardiovascular outcomes}

The current analysis showed that during a mean followup time period ranging from 52 weeks to 152 weeks, the primary endpoint was not significantly different in the treatment of T2DM patients with versus without DPP-4 inhibitors (OR: 0.95, 95\% CI: 0.86-1.04; $P=0.26$ ). Cardiovascular death (OR: 1.00, 95\% CI: 0.90-1.10; $P=0.93$ ), stroke (OR: $1.03,95 \% \mathrm{CI}: 0.89-1.18 ; P=0.72$ ), MI (OR: 0.97, 95\% CI: 0.88-1.07; $P=0.59$ ), all-cause mortality (OR: 0.84, 95\% CI: 0.59-1.18; $P=0.31$ ), hospitalization for cardiovascular complications (OR: 1.02, 95\% CI: $0.96-1.09 ; P=0.45)$ and hospitalization specifically for heart failure (OR: 1.05, 95\% CI: 0.90-1.23; $P=0.55)$ were also similarly manifested in both groups. The results have been represented in Figs. 2 and 3.

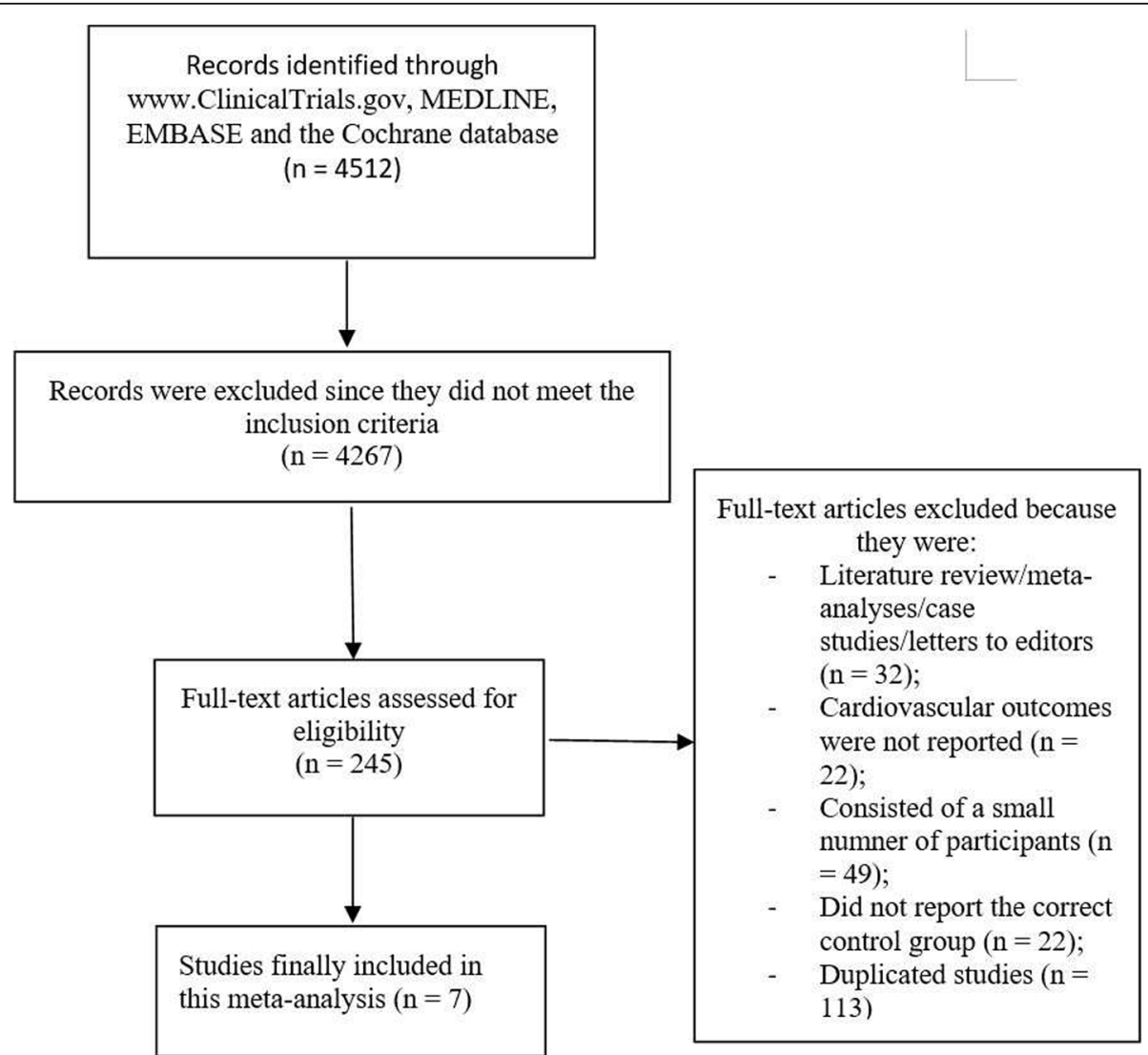

Fig. 1 Flow diagram showing the study selection 
Table 2 Main features of the studies

\begin{tabular}{lllll}
\hline Studies & $\begin{array}{l}\text { Type of } \\
\text { study }\end{array}$ & $\begin{array}{l}\text { Time period of patients' } \\
\text { enrollment }\end{array}$ & $\begin{array}{l}\text { Total no of patients assigned to DPP-4 } \\
\text { inhibitors (n) }\end{array}$ & $\begin{array}{l}\text { Total no of patients assigned to } \\
\text { control group (n) }\end{array}$ \\
\hline Gantz2017 [7] & RCT & $2012-2017$ & 2092 & 2100 \\
Green2015 [8] & RCT & $2008-2015$ & 7332 & 7339 \\
Park2015 [9] & OS & $2007-2011$ & 1866 & 5179 \\
Scirica2013 [10] & RCT & $2010-2011$ & 8280 & 8212 \\
Shih2016 [11] & OS & $2009-2013$ & 53,208 & 53,208 \\
Wang2015 [12] & OS & $2009-2011$ & 547 & 2735 \\
White2013 [13] & RCT & $2009-2013$ & 2701 & 2679 \\
Total no of patients (n) & & & 76,026 & 81,452
\end{tabular}

Abbreviations: RCT Randomized controlled trials, OS Observational studies, DPP-4 dipeptidyl peptidase 4

The main results have also been summarized in Table 4.

\section{Sensitivity analyses and publication bias}

Sensitivity analysis was carried out for the respective subgroups and consistent results were obtained throughout. When study Gantz2017 was excluded, results for primary endpoint (OR: 0.94, 95\% CI: 0.85-1.04; $P=0.25$ ), cardiovascular death (OR: 0.99, 95\% CI: 0.89-1.10; $P=0.88$ ), stroke (OR: $1.03,95 \%$ CI: 0.89-1.19; $P=0.66$ ), MI (OR: 0.98, 95\% CI: 0.89-1.09; $P=0.73$ ), hospitalization for cardiovascular complications (OR: 1.03, 95\% CI: 0.97-1.10; $P=0.36$ ), all-cause mortality (OR: 0.78, 95\% CI: $0.53-1.12 ; P=0.18)$ and hospitalization specifically for heart failure (OR: 1.09, 95\% CI: 0.96-1.23; $P=0.20$ ) were not significantly different compared to the main analysis. Consistent results were obtained throughout.

When study Green2015 was excluded, results for primary endpoint (OR: 0.93, 95\% CI: 0.84-1.02; $P=0.14$ ), cardiovascular death (OR: 0.95, 95\% CI: 0.83-1.08; $P=0.42$ ), stroke (OR: 1.07, 95\% CI: 0.89-1.28; $P=0.48$ ), MI (OR: 0.99, 95\% CI: 0.88-1.12; $P=0.86)$, hospitalization for cardiovascular complications (OR: 1.04, 95\% CI: 0.97-1.11;
$P=0.28$ ), all-cause mortality (OR: 0.80, 95\% CI: 0.55-1.18; $P=0.26)$ and hospitalization specifically for heart failure (OR: 1.05, 95\% CI: 0.83-1.32; $P=0.69$ ) were not significantly different compared to the main analysis. Consistent results were obtained throughout.

Even when study Shih2016, which was the largest study (with the highest number of participants) in this analysis, when excluded, results for the primary endpoint (OR: 0.99, 95\% CI: 0.93-1.07; $P=0.87$ ), all-cause mortality (OR: 0.92, 95\% CI: 0.72-1.17; $\mathrm{P}=0.48$ ), hospitalization specifically for heart failure (OR: 1.01, 95\% CI: $0.76-1.35 ; P=0.95)$, and hospitalization for cardiovascular complications (OR: 1.01, 95\% CI: 0.93-1.10; $P=0.80$ ) were not significantly different compared to the main results of this current analysis, that is, still consistent results were obtained throughout.

The same results were obtained even when the remaining studies were excluded by turn and new analyses were carried out.

Also, a low evidence of publication bias was observed throughout, across all the trials and observational cohorts that assessed the cardiovascular outcomes between the DPP-4 inhibitor versus the non-DPP-4 inhibitor group as shown in Fig. 4.

Table 3 Baseline features of the participants

\begin{tabular}{|c|c|c|c|c|c|c|}
\hline \multirow[t]{2}{*}{ Studies } & Age (years) & Males (\%) & Duration of DM (years) & $\mathrm{HbA} 1 \mathrm{c}(\%)$ & HBP (\%) & CS (\%) \\
\hline & DP/NDP & DP/NDP & DP/NDP & $\mathrm{DP} / \mathrm{NDP}$ & $\mathrm{DP} / \mathrm{NDP}$ & DP/NDP \\
\hline Gantz2017 & $63.7 / 63.6$ & $69.6 / 70.7$ & $12.0 / 12.1$ & $8.00 / 8.00$ & $95.1 / 95.6$ & $14.3 / 14.5$ \\
\hline Green2015 & - & - & - & - & - & - \\
\hline Park2015 & $61.0 / 63.0$ & $66.2 / 62.2$ & - & $7.60 / 7.20$ & $79.7 / 80.4$ & - \\
\hline Scirica2013 & $65.1 / 65.0$ & $66.6 / 67.3$ & $10.3 / 10.3$ & $8.00 / 8.00$ & $81.2 / 82.4$ & - \\
\hline Shih2016 & $74.5 / 74.5$ & $46.2 / 46.2$ & $8.70 / 8.70$ & - & $90.9 / 90.9$ & - \\
\hline Wang2015 & $66.0 / 65.9$ & 64.0/63.7 & - & - & $75.1 / 75.9$ & - \\
\hline White2013 & $61.0 / 61.0$ & $67.7 / 68.0$ & $7.10 / 7.30$ & $8.00 / 8.00$ & $82.5 / 83.6$ & $13.0 / 14.3$ \\
\hline
\end{tabular}

Abbreviations: DM Diabetes mellitus, HbA1c Glycated hemoglobin, HBP High blood pressure, CS Current smoker, DP Dipeptidyl peptidase 4 inhibitor group, NDP Non-dipeptidyl peptidase 4 inhibitor group 


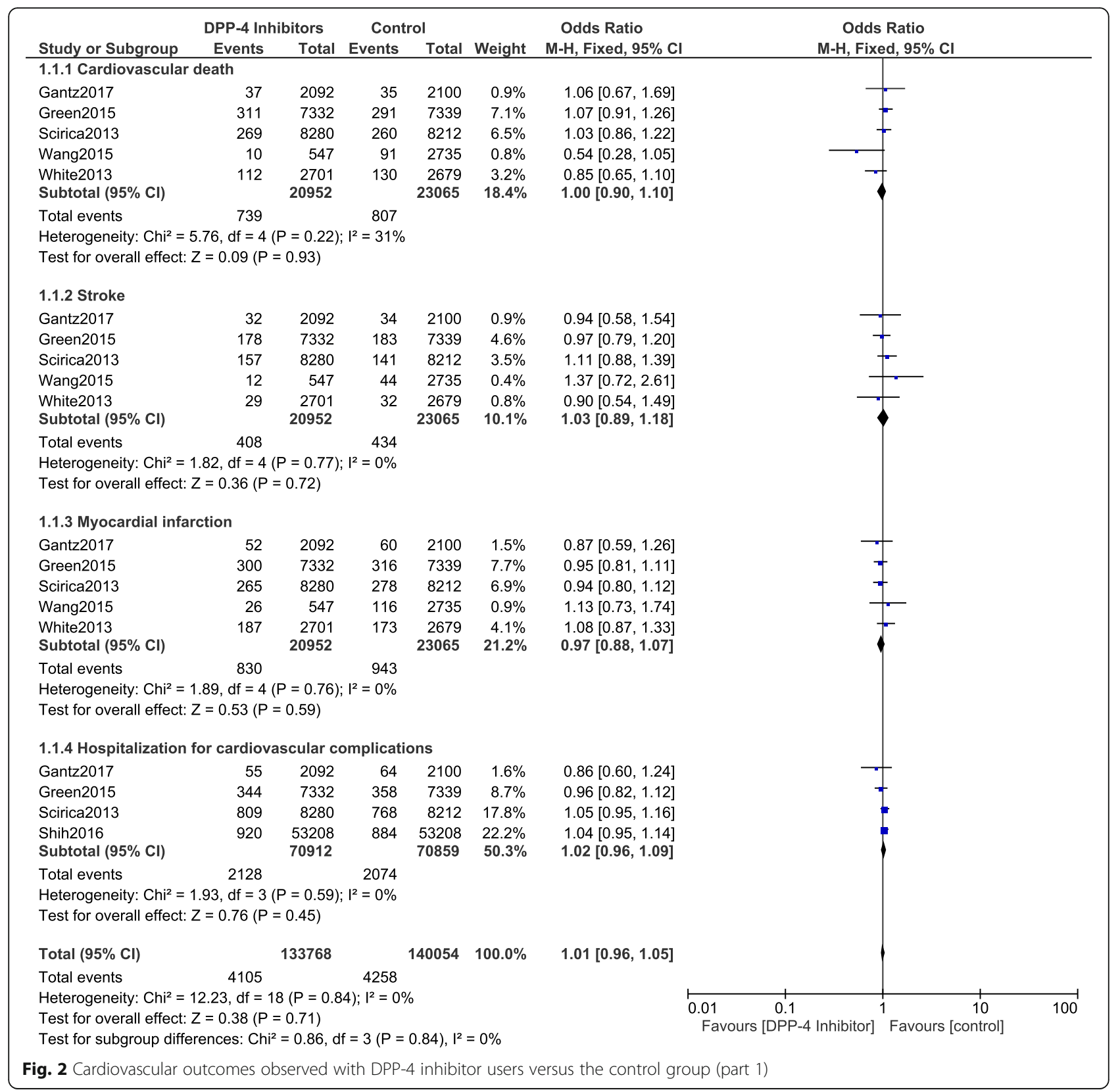

\section{Discussion}

DPP-4 inhibitors are newer oral anti-diabetic agents with high expectations. Their mechanism of action is based on the prolongation of the activity of glucagon-like peptide 1 (GLP1), the gastric-inhibitory peptide, as well as other incretins by restraining their breakdown [14].

The current analysis which included a very large total number of participants showed that DPP-4 inhibitors were not associated with significantly higher cardiovascular outcomes in comparison to DDP-4 inhibitor non-users. Cardiovascular death, MI, hospitalization for cardiovascular complications and specifically for heart failure, were similarly manifested with DPP-4 inhibitors in these patients with T2DM.

The SAVOR-TIMI 53 trial [10] which was a randomized, multicenter, double blind placebo-controlled phase 4 trial which demonstrated the cardiovascular safety and efficacy of DPP-4 inhibitors also did not show any increase in cardiovascular events associated with the use of this group of drugs. However, an increased rate of hospitalization due to heart failure was observed.

In the EXAMINE trial [13], whereby 5380 participants underwent randomization, the authors concluded that no increase in adverse cardiovascular events were 


\begin{tabular}{|c|c|c|c|c|c|c|c|c|c|}
\hline \multirow[b]{2}{*}{ Study or Subgroup } & \multicolumn{2}{|c|}{ DPP-4 Inhibitors } & \multicolumn{2}{|c|}{ Control } & \multirow[b]{2}{*}{ Weight } & \multirow{2}{*}{$\begin{array}{l}\text { Odds Ratio } \\
\text { M-H, Random, } 95 \% \mathrm{Cl}\end{array}$} & \multirow{2}{*}{\multicolumn{3}{|c|}{$\begin{array}{c}\text { Odds Ratio } \\
\text { M-H, Random, } 95 \% \mathrm{CI}\end{array}$}} \\
\hline & Events & Total & Events & Total & & & & & \\
\hline \multicolumn{10}{|c|}{ 1.1.1 Primary endpoint } \\
\hline Gantz2017 & 114 & 2092 & 114 & 2100 & $5.9 \%$ & $1.00[0.77,1.31]$ & & & \\
\hline Green2015 & 609 & 7257 & 602 & 7266 & $6.8 \%$ & $1.01[0.90,1.14]$ & & & \\
\hline Scirica2013 & 613 & 8280 & 609 & 8212 & $6.8 \%$ & $1.00[0.89,1.12]$ & $t$ & & \\
\hline Shih2016 & 2958 & 53208 & 3471 & 53208 & $7.0 \%$ & $0.84[0.80,0.89]$ & $\cdot$ & & \\
\hline Wang2015 & 45 & 547 & 233 & 2735 & $5.5 \%$ & $0.96[0.69,1.34]$ & 7 & - & \\
\hline White2013 & 305 & 2701 & 316 & 2679 & $6.5 \%$ & $0.95[0.81,1.13]$ & & & \\
\hline Subtotal $(95 \% \mathrm{Cl})$ & & 74085 & & 76200 & $38.5 \%$ & $0.95[0.86,1.04]$ & & & \\
\hline Total events & 4644 & & 5345 & & & & & & \\
\hline \multicolumn{10}{|c|}{ Heterogeneity: $\mathrm{Tau}^{2}=0.01 ; \mathrm{Chi}^{2}=14.37, \mathrm{df}=5(P=0.01) ; \mathrm{I}^{2}=65 \%$} \\
\hline \multicolumn{10}{|c|}{ Test for overall effect: $Z=1.14(P=0.26)$} \\
\hline \multicolumn{10}{|c|}{ 1.1.2 All-cause mortality } \\
\hline Gantz2017 & 64 & 2092 & 50 & 2100 & $5.2 \%$ & $1.29[0.89,1.88]$ & & $=$ & \\
\hline Green2015 & 547 & 7332 & 537 & 7339 & $6.7 \%$ & $1.02[0.90,1.16]$ & & & \\
\hline Park2015 & 76 & 1866 & 393 & 5179 & $6.0 \%$ & $0.52[0.40,0.66]$ & - & & \\
\hline Scirica2013 & 420 & 8280 & 378 & 8212 & $6.7 \%$ & $1.11[0.96,1.28]$ & F & 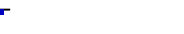 & \\
\hline Shih2016 & 4151 & 53208 & 7162 & 53208 & $7.0 \%$ & $0.54[0.52,0.57]$ & - & & \\
\hline White2013 & 153 & 2701 & 173 & 2679 & $6.2 \%$ & $0.87[0.69,1.09]$ & & & \\
\hline Subtotal $(95 \% \mathrm{Cl})$ & & 75479 & & 78717 & $37.8 \%$ & $0.84[0.59,1.18]$ & & & \\
\hline Total events & 5411 & & 8693 & & & & & & \\
\hline \multirow{2}{*}{\multicolumn{10}{|c|}{$\begin{array}{l}\text { Heterogeneity: } \text { Tau }^{2}=0.18 ; \mathrm{Chi}^{2}=191.67, \mathrm{df}=5(\mathrm{P}<0.00001) ; \mathrm{I}^{2}=97 \% \\
\text { Test for overall effect: } Z=1.01(\mathrm{P}=0.31)\end{array}$}} \\
\hline & & & & & & & & & \\
\hline \multicolumn{10}{|c|}{ 1.1.3 Hospitalization specifically for heart failure } \\
\hline Gantz2017 & 20 & 2092 & 33 & 2100 & $3.9 \%$ & $0.60[0.35,1.06]$ & & & \\
\hline Green2015 & 228 & 7332 & 229 & 7339 & $6.4 \%$ & $1.00[0.83,1.20]$ & & & \\
\hline Scirica2013 & 289 & 8280 & 228 & 8212 & $6.5 \%$ & $1.27[1.06,1.51]$ & & - & \\
\hline Shih2016 & 920 & 53208 & 884 & 53208 & $6.9 \%$ & $1.04[0.95,1.14]$ & $t$ & & \\
\hline Subtotal $(95 \% \mathrm{Cl})$ & & 70912 & & 70859 & $23.7 \%$ & $1.05[0.90,1.23]$ & & & \\
\hline Total events & 1457 & & 1374 & & & & & & \\
\hline \multicolumn{10}{|c|}{ Heterogeneity: $\mathrm{Tau}^{2}=0.01 ; \mathrm{Chi}^{2}=8.35, \mathrm{df}=3(\mathrm{P}=0.04) ; \mathrm{I}^{2}=64 \%$} \\
\hline \multicolumn{10}{|c|}{ Test for overall effect: $Z=0.59(P=0.55)$} \\
\hline Total $(95 \% \mathrm{Cl})$ & & 220476 & & 225776 & $100.0 \%$ & $0.92[0.77,1.08]$ & 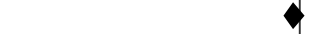 & & \\
\hline Total events & 11512 & & 15412 & & & & & & \\
\hline Heterogeneity: $\mathrm{Tau}^{2}=$ & $0.10 ; \mathrm{Chi}^{2}=$ & $489.55, d$ & $f=15(P$ & $<0.0000$ & $1) ; I^{2}=97 \%$ & & $0.01 \quad 0.1$ & 10 & 100 \\
\hline Test for overall effect & $Z=1.02(P$ & $=0.31)$ & & & & & Favours [DPP-4 Inhibitor] & Favours [control] & \\
\hline Test for subgroup diff & rences: Chi & $=1.88, \mathrm{~d}$ & lf $=2(P=$ & $0.39), 1^{2}$ & $=0 \%$ & & & & \\
\hline g. 3 Cardiovascular & itcomes & ervec & h & inhi & & & & & \\
\hline
\end{tabular}

observed in those patients who were recently affected by acute coronary syndrome.

Even in the TECOS trial [8], which was also a randomized, double-blind study involving more than 10, 000 participants, the authors did not observe any significant increase in cardiovascular outcomes with the use of DPP-4 inhibitors for the treatment of patients with
T2DM. However, compared to the SAVOR-TIMI 53 trial, there was no increase in hospitalization due to heart failure in the TECOS trial.

Another open observational non-crossover retrospective cohort study which was conducted between June 2012 and December 2013, and which compared the cardiovascular efficacy and safety of linagliptin,

Table 4 Results of this analysis with a large population size

\begin{tabular}{lllll}
\hline Cardiovascular outcomes assessed & No of studies involved (n) & OR with 95\% Cl & $\mathrm{P}$ value & $\mathrm{I}^{2}$ value (\%) \\
\hline Primary endpoint & 6 & $0.95[0.86-1.04]$ & 0.26 & 65 \\
Cardiovascular death & 5 & $1.00[0.90-1.10]$ & 0.93 & 31 \\
All-cause mortality & 6 & $0.84[0.59-1.18]$ & 0.31 & 97 \\
Stroke & 5 & $1.03[0.89-1.18]$ & 0.72 & 0 \\
Myocardial infarction & 5 & $0.97[0.88-1.07]$ & 0.59 & 0 \\
Hospitalization for cardiovascular complications & 4 & $1.02[0.96-1.09]$ & 0.45 & 0 \\
Hospitalization specifically for heart failure & 4 & $1.05[0.90-1.23]$ & 0.55 & 64 \\
\hline
\end{tabular}

Abbreviations: OR Odds ratios, $\mathrm{Cl}$ Confidence intervals 


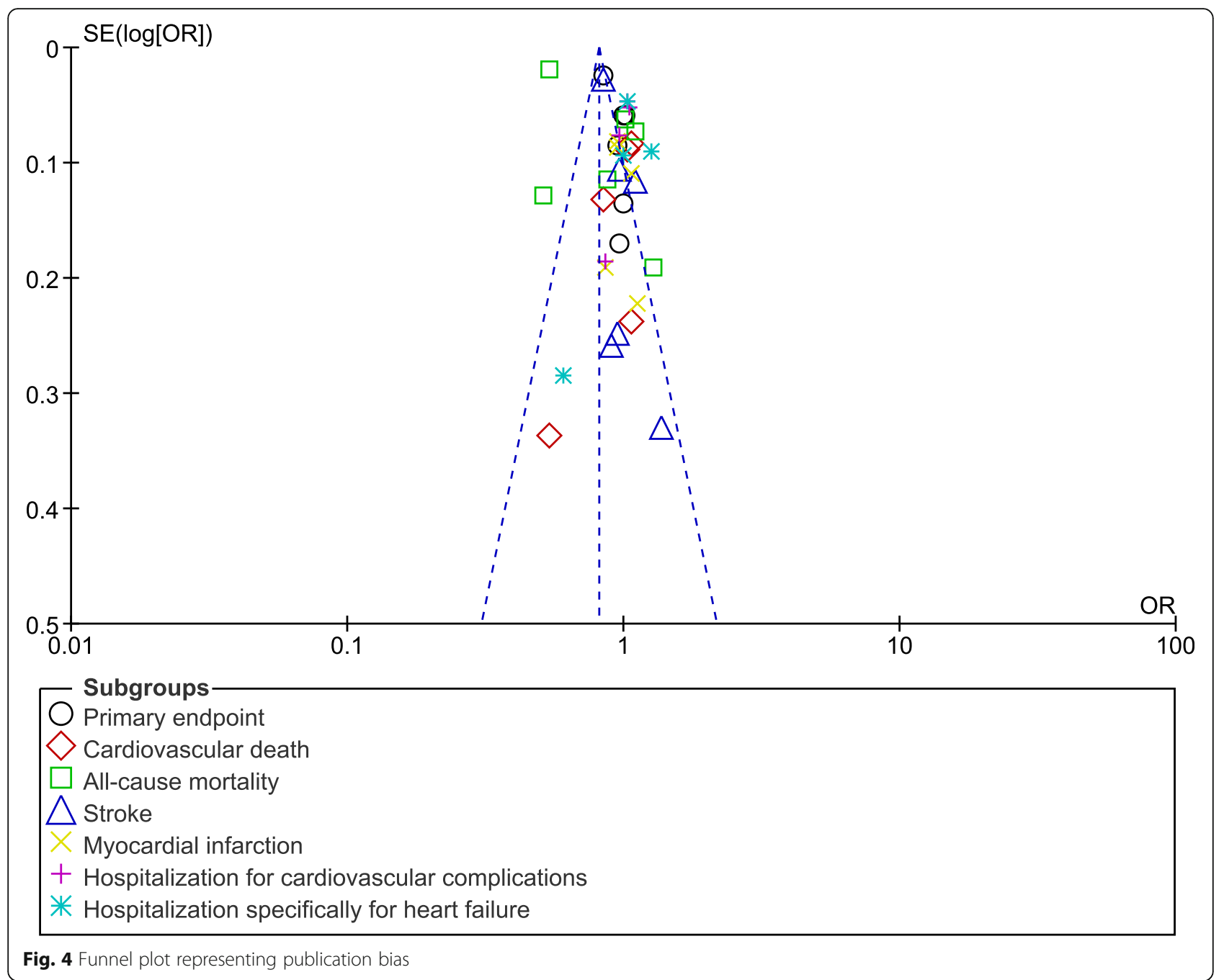

another DPP-4 inhibitor, also did not show any significant increase in cardiovascular events with the drug in these patients with T2DM and acute coronary syndrome [15]. However, the forthcoming CARMELINA trial which aimed to demonstrate the effects of linagliptin on cardiovascular and renal outcomes might further add information to DPP-4 inhibitors and cardiovascular events [16].

\section{Limitations}

First of all, the inclusion of data which were extracted from observational studies have increased the heterogeneity during subgroup analysis. This might be one major limitation of this analysis. Secondly, the duration of T2DM was not similar in all the studies. In addition, the follow-up time periods were different in different studies, and this might have affected the results. Also, different DPP-4 inhibitors were combined prior to analysis and this might have also contributed to the limitations observed in this analysis.

\section{Conclusions}

The current analysis showed that treatment with DPP-4 inhibitors did not significantly increase cardiovascular outcomes in these patients with T2DM indicating that those drugs might be safe to use in terms of cardiovascular events.

\section{Abbreviations}

CVD: Cardiovascular diseases; DPP-4: Dipeptidyl peptidase 4; OR: Odds ratios; T2DM: Type 2 diabetes mellitus

\section{Acknowledgements}

All named authors meet the International Committee of Medical Journal Editors (ICMJE) criteria for authorship for this article, take responsibility for the integrity of the work as a whole, and have given their approval for this version to be published. 


\section{Funding}

No funding or sponsorship was received for this study or publication of this article.

\section{Availability of data and materials}

All data and materials used in this research are freely available in electronic databases. References have been provided.

\section{Authors' contributions}

$\mathrm{DL}, \mathrm{BJ}, \mathrm{WC}$ and PY were responsible for the conception and design, acquisition of data, analysis and interpretation of data, drafting the initial manuscript and revising it critically for important intellectual content. DL and BJ wrote the final draft of the manuscript. DL, BJ, WC and PY approved the final manuscript as it is. $\mathrm{DL}$ and $\mathrm{BJ}$ are co-first authors.

\section{Ethics approval and consent to participate}

Ethical approval was not applicable for this systematic review and metaanalysis.

\section{Consent for publication}

Not applicable.

\section{Competing interests}

The authors Dr. Dan Liu, Dr. Biao Jin, Dr. Wei Chen, and Dr. Peng Yun declare that they have no competing interests.

\section{Publisher's Note}

Springer Nature remains neutral with regard to jurisdictional claims in published maps and institutional affiliations.

\section{Author details}

'Department of Endocrinology, Jingzhou First Peoples Hospital, Jingzhou, Hubei, People's Republic of China. ${ }^{2}$ Department of Critical Care Medicine, Jingzhou First Peoples Hospital, Jingzhou, Hubei, People's Republic of China.

Received: 11 January 2019 Accepted: 26 February 2019

Published online: 04 March 2019

\section{References}

1. Benjamin EJ, Blaha MJ, Chiuve SE, Cushman M, Das SR, Deo R, de Ferranti SD, Floyd J, Fornage M, Gillespie C, Isasi CR, Jiménez MC, Jordan LC, Judd SE, Lackland D, Lichtman JH, Lisabeth L, Liu S, Longenecker CT, Mackey RH, Matsushita K, Mozaffarian D, Mussolino ME, Nasir K, Neumar RW, Palaniappan L, Pandey DK, Thiagarajan RR, Reeves MJ, Ritchey M, Rodriguez CJ, Roth GA, Rosamond WD, Sasson C, Towfighi A, Tsao CW, Turner MB, Virani SS, Voeks JH, Willey JZ, Wilkins JT, Wu JH, Alger HM, Wong SS, Muntner P, American Heart Association Statistics Committee and Stroke Statistics Subcommittee. Heart disease and stroke Statistics2017 update: a report from the American Heart Association. Circulation. 2017;135(10):e146-603.

2. Lago RM, Singh PP, Nesto RW. Congestive heart failure and cardiovascular death in patients with prediabetes and type 2diabetes given thiazolidinediones: a meta-analysis of randomised clinical trials. Lancet. 2007;370(9593):1129-36.

3. Hiatt WR, Kaul S, Smith RJ. The cardiovascular safety of diabetes drugs--insights from the rosiglitazone experience. N Engl J Med. 2013;369(14):1285-7.

4. Zhong J, Maiseyeu A, Davis SN, Rajagopalan S. DPP4 in cardio-metabolic disease: recent insights from the laboratory and clinical trials of DPP4 inhibition. Circ Res. 2015;116(8):1491-504.

5. Liberati A, Altman DG, Tetzlaff J, et al. The PRISMA statement for reporting systematic reviews and meta-analyses of studies that evaluate healthcareinterventions: explanation and elaboration. BMJ. 2009;339:b2700.

6. Higgins JP, et al. Assessing risk of bias in included studies. In: Cochrane handbook for systematic reviews of interventions: Wiley; 2008. p. 187-241.

7. Gantz I, Chen M, Suryawanshi S, Ntabadde C, Shah S, O'Neill EA, Engel SS, Kaufman KD, Lai E. A randomized, placebo-controlled study of the cardiovascular safety of the once-weekly DPP-4inhibitor omarigliptin in patients with type 2 diabetes mellitus. Cardiovasc Diabetol. 2017;16(1):112.

8. Green JB, Bethel MA, Armstrong PW, Buse JB, Engel SS, Garg J, Josse R, Kaufman KD, Koglin J, Korn S, Lachin JM, McGuire DK, Pencina MJ, Standl E,
Stein PP, Suryawanshi S, Van de Werf F, Peterson ED, Holman RR, TECOS Study Group. Effect of Sitagliptin on cardiovascular outcomes in type 2 diabetes. N Engl J Med. 2015;373(3):232-42.

9. Park HE, Jeon J, Hwang IC, Sung J, Lee SP, Kim HK, Cho GY, Sohn DW, Kim YJ. Effect of dipeptidyl Peptidase-4 inhibitor on all-cause mortality and coronary Revascularizationin diabetic patients. J Cardiovasc Ultrasound. 2015:23(4):233-43

10. Scirica BM, Bhatt DL, Braunwald E, Steg PG, Davidson J, Hirshberg B, Ohman P. Frederich R, Wiviott SD, Hoffman EB, Cavender MA, Udell JA, Desai NR, Mosenzon O, McGuire DK, Ray KK, Leiter LA, Raz I, SAVOR-TIMI 53 Steering Committee and Investigators. Saxagliptin and cardiovascular outcomes in patients with type 2 diabetes mellitus. N Engl J Med. 2013;369(14):1317-26.

11. Shih CJ, Chen HT, Kuo SC, Ou SM, Chen YT. Cardiovascular outcomes of dipeptidyl Peptidase-4 inhibitors in elderly patients with type 2 diabetes: a Nationwide study. J Am Med Dir Assoc. 2016;17(1):59-64

12. Wang SH, Chen DY, Lin YS, Mao CT, Tsai ML, Hsieh MJ, Chou CC, Wen MS, Wang CC, Hsieh IC, Hung KC, Chen TH. Cardiovascular outcomes of Sitagliptin in type 2 diabetic patients with acute Myocardiallnfarction, a population-based cohort study in Taiwan. PLoS One. 2015;10(6):e0131122.

13. White WB, Cannon CP, Heller SR, Nissen SE, Bergenstal RM, Bakris GL, Perez AT, Fleck PR, Mehta CR, Kupfer S, Wilson C, Cushman WC, Zannad F, EXAMINE Investigators. Alogliptin after acute coronary syndrome in patients with type 2 diabetes. N Engl J Med. 2013;369(14):1327-35.

14. Krishna R, Addy C, Tatosian D, Glasgow XS, Gendrano lii IN, Robberechts M, Haazen W, de Hoon JN, Depré M, Martucci A, Peng JZ, Johnson-Levonas AO, Wagner JA, Stoch SA. Pharmacokinetics and pharmacodynamics of Omarigliptin, a once-weekly dipeptidyl Peptidase-4 (DPP-4) inhibitor, after single and multiple doses in healthy subjects. J Clin Pharmacol. 2016:56(12):1528-37.

15. Li YR, Tsai SS, Chen DY, Chen ST, Sun JH, Chang HY, Liou MJ, Chen $\mathrm{TH}$. Linagliptin and cardiovascular outcomes in type 2 diabetes after acute coronary syndrome or acute ischemic stroke. Cardiovasc Diabetol. 2018:17(1):2.

16. Rosenstock J, Perkovic V, Alexander JH, Cooper ME, Marx N, Pencina MJ, Toto RD, Wanner C, Zinman B, Baanstra D, Pfarr E, Mattheus M, Broedl UC, Woerle HJ, George JT, von Eynatten M, McGuire DK, CARMELINA investigators. Rationale, design, and baseline characteristics of the CArdiovascular safety and renal microvascular outcomE study with LINAgliptin (CARMELINA ${ }^{\oplus}$ ): a randomized, double-blind, placebo-controlled clinical trial in patients with type 2 diabetes and high cardio-renal risk. Cardiovasc Diabetol. 2018;17(1):39.

Ready to submit your research? Choose BMC and benefit from:

- fast, convenient online submission

- thorough peer review by experienced researchers in your field

- rapid publication on acceptance

- support for research data, including large and complex data types

- gold Open Access which fosters wider collaboration and increased citations - maximum visibility for your research: over $100 \mathrm{M}$ website views per year

At BMC, research is always in progress.

Learn more biomedcentral.com/submissions 